
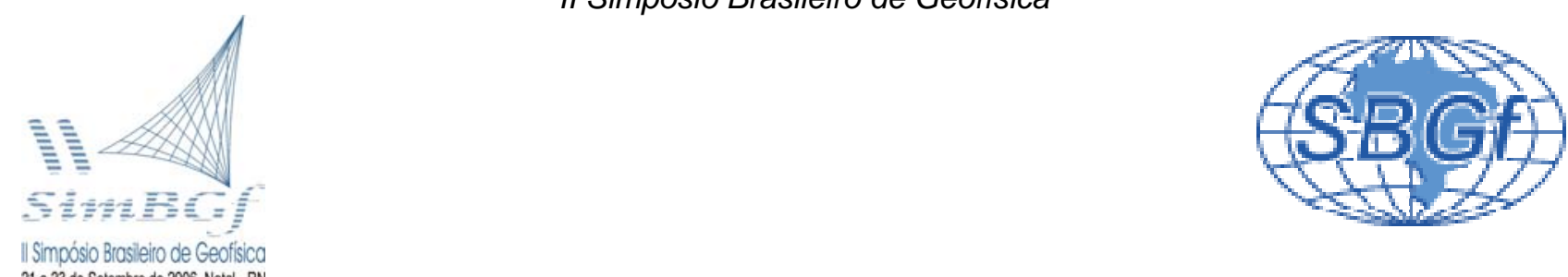

21 a 23 de Setembro de 2006, Natal - RN

\title{
Sísmica de refração rasa com imageamento tomográfico em locais com estratos anisotrópicos
}

João Carlos Dourado - Departamento de Geologia Aplicada - IGCE - UNESP

Walter Malagutti Filho - Departamento de Geologia Aplicada - IGCE - UNESP

Copyright 2006, SBGf - Sociedade Brasileira de Geofísica

Este texto foi preparado para a apresentação no II Simpósio de Geofísica da Sociedade Brasileira de Geofísica, Natal, 21-23 de setembro de 2006. Seu conteúdo foi revisado pela Comissão Tecno-científica do I I SR-SBGf mas não necessariamente representa a opinião da SBGf ou de seus associados. E proibida a reprodução total ou parcial deste material para propósitos comerciais sem prévia autorização da SBGf.

\section{Resumo}

Este trabalho compara, através de dois exemplos reais, a interpretação da refração sísmica convencional com a interpretação utilizando inversão tomográfica com o objetivo de avaliar as vantagens e limitações dos dois procedimentos. Os resultados mostram que em situações favoráveis ao ensaio de refração (camadas homogêneas e com geometria sub-horizontal) os dois procedimentos são similares, mas em locais onde existe anisotropia e interfaces muito irregulares a interpretação através de inversão tomográfica resulta em um modelo com ajuste melhor do que o método convencional.

\section{Introdução}

A sísmica de refração, na geofísica aplicada, teve seu desenvolvimento no início do século $X X$, com as primeiras aplicações voltadas para florescente indústria da prospecção petrolífera (McGee \& Palmer, 1967). Até meados dos anos 50 ela teve bastante emprego nesta área, mas sendo superada e substituída rapidamente pela sísmica de reflexão a partir deste período.

O abandono da sísmica de refração convencional para estudos petrolífero foi devido às limitações da técnica e pelo avanço do imageamento sísmico proporcionado pelo desenvolvimento técnica de reflexão, fortemente financiado pela indústria do petróleo.

Em contrapartida, a sísmica de refração se tornou a técnica sísmica mais utilizada para estudos rasos, principalmente nas áreas de Geologia de Engenharia e Engenharia Civil (Sjogren, 2000), devido à simplicidade de processamento dos sinais e a facilidade de identificação das primeiras chegadas das ondas sísmicas nos sismogramas, uma vez que o imageamento sísmico executado pela sísmica de reflexão não possui resolução suficiente para estudos rasos.

Recentemente, a partir do final da década de 90, surgiram programas que possibilitam a inversão tomográfica a partir dos tempos de propagação das ondas refratadas e diretas, comumente obtidos em ensaios de refração (Sheehan et Al., 2005) Esta inversão tomográfica, por sua vez, produz imageamento de subsuperfície baseado em velocidade de propagação de ondas sísmicas.

O objetivo deste trabalho é comparar, em dois exemplos, a interpretação da refração sísmica convencional com interpretação com inversão tomográfica e desta maneira avaliar as vantagens e limitações dos dois procedimentos.

\section{Ensaios de sísmica de refração}

Foram realizados ensaios de sísmica de refração em dois locais. O primeiro local foi considerado como ideal para realização de ensaios e refração e o segundo em um local problemático para este tipo de ensaio, pois os estratos sísmicos não podem ser considerados como homogêneos devido a presença de sedimentos aluvionares encaixados no solo de alteração de diabásio a interface solo rocha ser muito irregular.

Nos dois ensaios foi utilizado um sismógrafo fabricado pela OYO, modelo DAS1 de 24 canais. Foram utilizado geofones verticais com freqüência de ressonância de 100 hz e impacto de marreta como fonte de ondas sísmicas.

Para a interpretação foi utilizada a técnica do "Delaytime" para a interpretação convencional e para o imageamento tomográfico foi utilizada a técnica de aproximação não linear dos mínimos quadrados para a inversão, o software utilizado foi o Seisimager /2D da OYO.

\section{Local 1 - situação ideal}

Este local, considerado como ideal para a realização dos ensaios de sísmica de refração, possui topografia plana e um perfil de dois estratos sísmicos: o primeiro estrato é composto por solo arenoso, seco e bastante homogêneo, resultante do intemperismo da Formação Rio Claro e o segundo estrato sísmico é composto pelo mesmo tipo de solo abaixo do NA, portanto saturado.

O arranjo de campo para este ensaio consistiu de uma base sísmica de 24 geofones, separados entre si de 2 metros. Foram feitos 3 pontos de impactos de marreta nesta base, uma em cada extremidade, com "offset" de 2 metros e um no centro do arranjo, ou seja separado 1 metro dos geofones 12 e 13. A Figura 1 mostra o sismograma de um impacto próximo ao geofone 1 e os tempos de propagação dos outros sismogramas representados pelas linhas verdes.. 


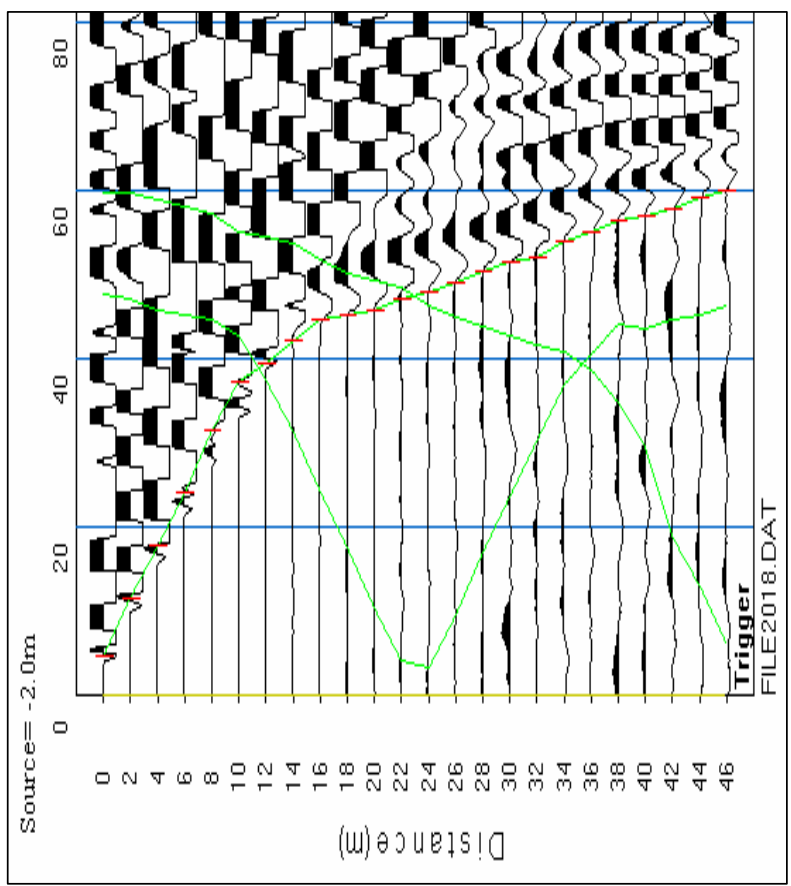

Figura 1 - Sismograma do impacto próximo ao geofone 1. Notar que, pelas retas obtidas através das primeiras chegadas das ondas diretas e refratadas, a área possui estratos bastante homogêneos.

A plotagem dos três sismogramas resultou em um gráfico tempoxdistância mostrado na Figura 2.

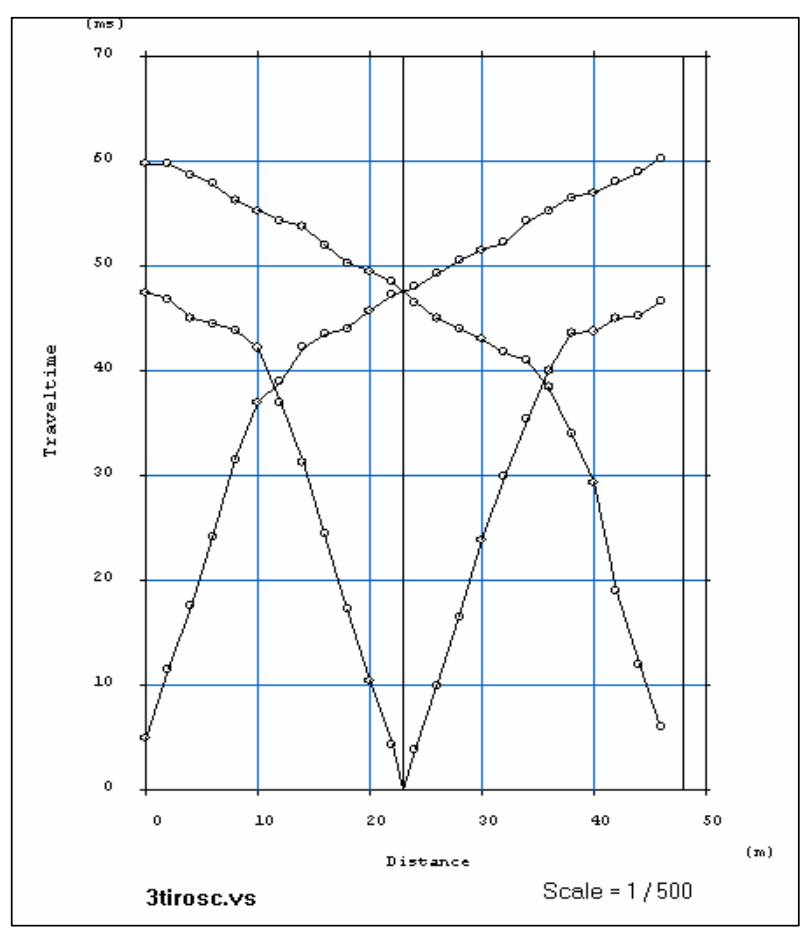

Figura 2 - Gráfico tempoxdistância para o Local 1. Nota o caráter "comportado" dos estratos sísmicos.
A interpretação convencional, utilizando duas camadas, forneceu o perfil sísmico mostrado na Figura 3, onde a primeira camada possui a velocidade de $300 \mathrm{~m} / \mathrm{s}$ e o refrator a velocidade de $1600 \mathrm{~m} / \mathrm{s}$.

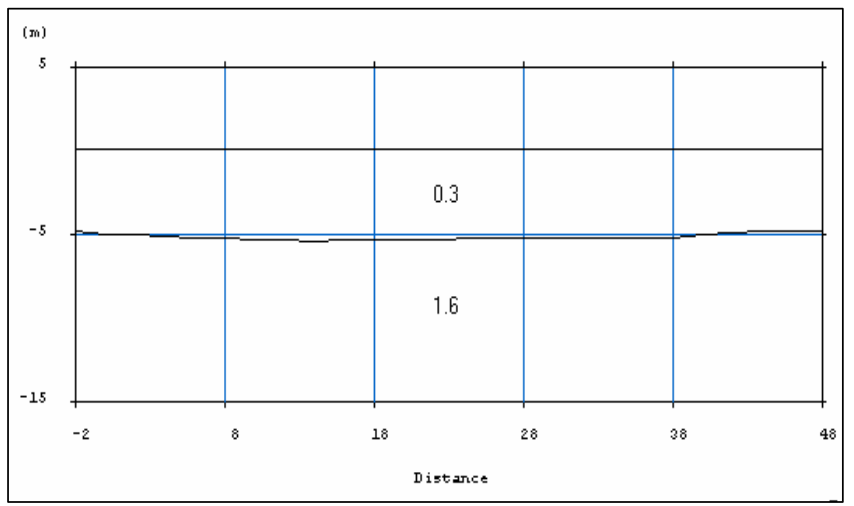

Figura 3 - Perfil sísmico do local 1, onde o refrator com velocidade de $1600 \mathrm{~m} / \mathrm{s}$ encontra-se na profundidade de 5 metros..

A interpretação utilizando a inversão tomográfica forneceu a imagem sísmica do Local 1, mostrado na Figura 4.

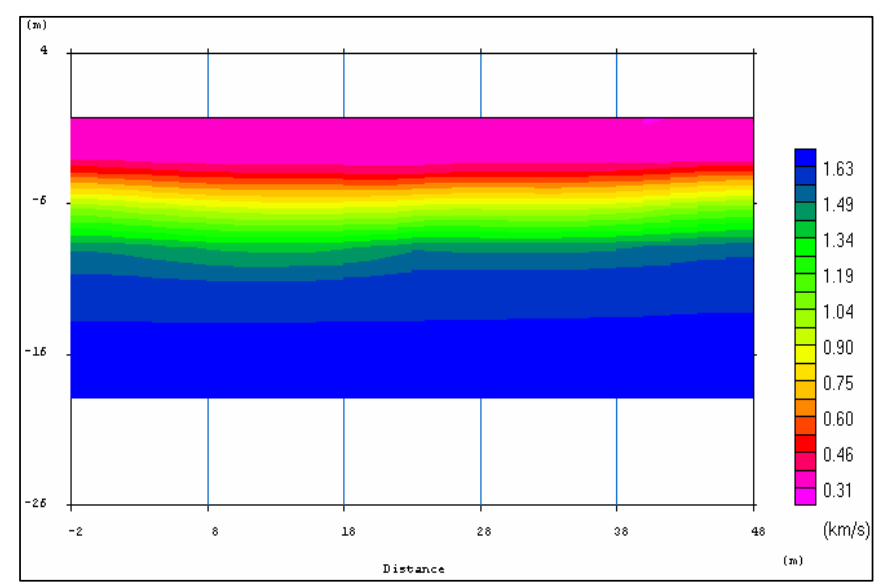

Figura 4 - Perfil do imageamento sísmico do local 1 , notar a correspondência bastante boa com o perfil obtido com a interpretação convencional.

\section{Local 2 - situação desfavorável}

Em contrapartida ao local 1, este local é considerado como desfavorável à utilização da sísmica de refração pois possui a primeira camada com anisotropia de velocidade de propagação da onda $P$ e um refrator muito irregular, apesar de possuir uma topografia plana. Este local está em uma área onde ocorre diabásio do Grupo Serra Geral.

Nesta área optou-se por fazer um arranjo de 24 canais onde os geofones estão espaçados de 1 metro entre si, para aumentar a resolução horizontal. Foram utilizados também 5 pontos de geração de ondas, sendo 2 pontos externos com "offset" de 10 em cada terminação do arranjo, 2 pontos nas extremidade do arranjo (entre os geofones 1 e 2 e os geofones 23 e 24) e 1 ponto central 
entre os geofones 12 e 13. A Figura 5 mostra o sismograma obtido no ponto localizado entre os geofones 1 e 2.

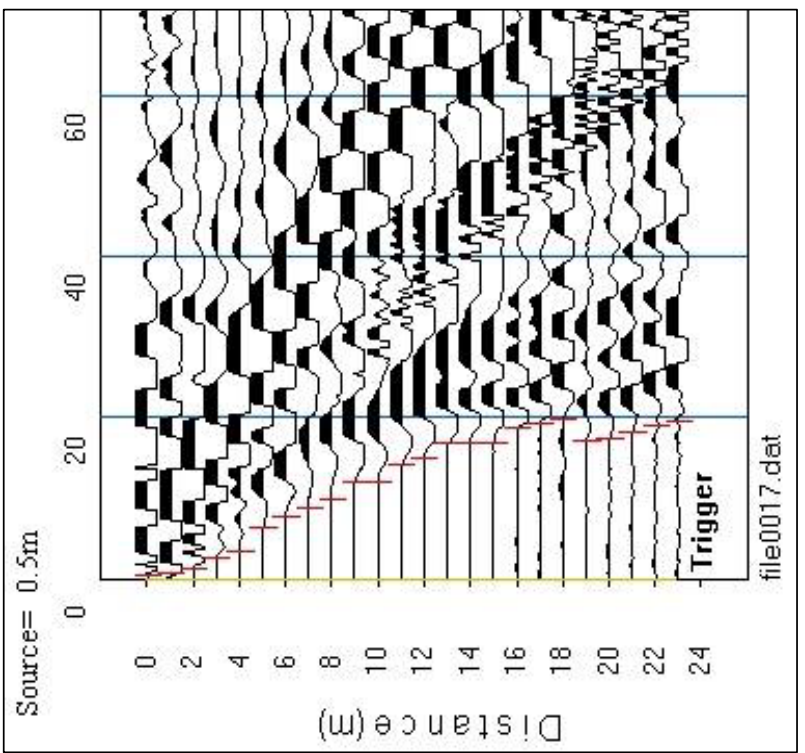

Figura 5 - Sismograma obtido com a fonte de ondas entre os geofones 1 e 2. Os traços horizontais em vermelho mostram a primeira chegada das ondas $P$. Notar a irregularidade do alinhamento destes traços.

Através dos 5 sismogramas obtidos foram construídas as curvas tempoXdistância que são mostradas na Figura 6 .

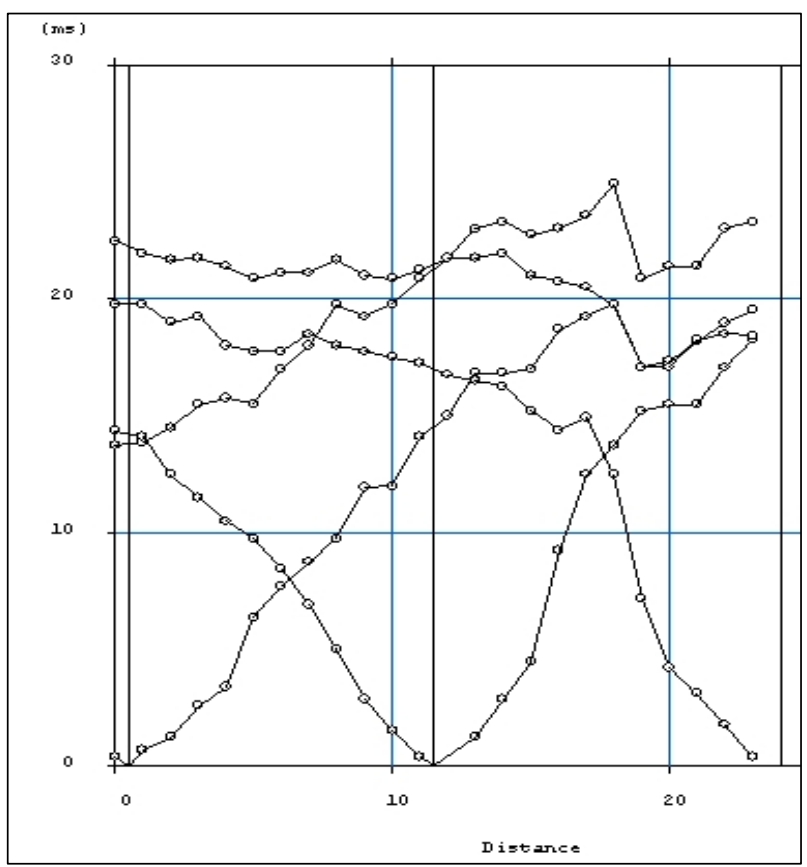

Figura 6 - Gráfico tempoxdistância para o Local 2, no eixo $X$ encontra-se a distância em metros e no eixo $Y$ o tempo em milisegundos. Nota o caráter heterogeneo dos estratos sísmicos.
O gráfico da Figura 6 mostra a existência de uma grande heterogeneidade neste local, marcada pelas mudanças bruscas na inclinação das "retas" correspondentes às primeiras chegadas das ondas diretas indicando uma variação lateral de velocidade. As variações nas "retas" das ondas refratadas indicam que as interfaces entre os refratores presentes são também bastante irregulares.

Para se fazer a interpretação convencional utilizou-se um modelo de 3 camadas e obteve-se o perfil sísmico mostrado na Figura 7. Neste perfil a primeira camada correspondente ao solo de alteração de diabásio (terra roxa) possui velocidade de propagação da onda $P$ de 0,8 $\mathrm{km} / \mathrm{s}$, a camada intermediaria de $2,0 \mathrm{~km} / \mathrm{s}$ corresponde ao diabásio alterado e o refrator com velocidade de 4,5 $\mathrm{km} / \mathrm{s}$ corresponde ao diabásio são.

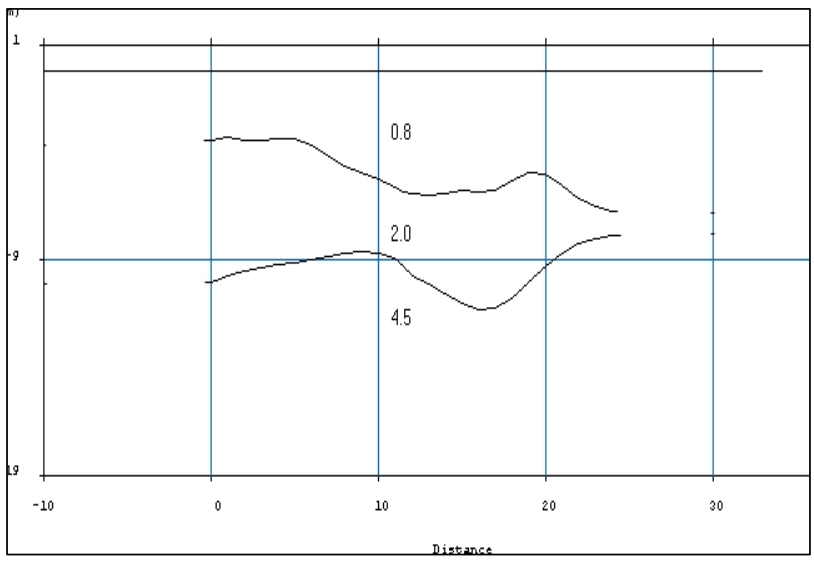

Figura 7 - Perfil sísmico do local 2, mostrando as três camadas presentes.

A interpretação mostrando a inversão tomográfica é mostrada na imagem da Figura 8.

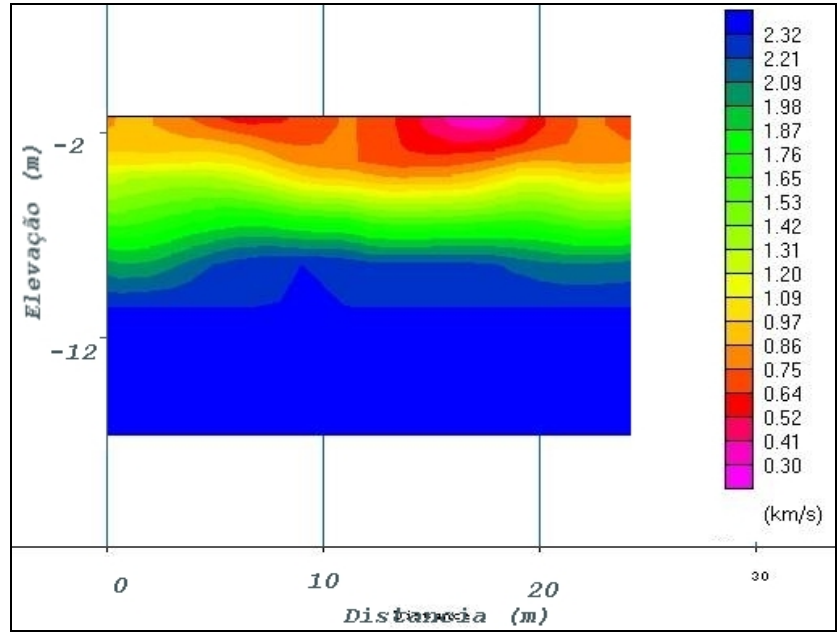

Figura 8 - Perfil do imageamento sísmico do local 2, notar a existência de variações na velocidade da primeira camada. 


\section{Discussão e Conclusões}

Uma simples comparação visual com os resultados obtidos para o Local 1, pode-se verificar que tanto a interpretação convencional como a interpretação utilizando inversão tomográfica produzem seções sísmicas similares.
Para comprovar este fato, foram feitas as modelagens diretas dos dois perfis sísmicos obtidos, para se obter as curvas tempoXdistância através de um algoritmo de raytracing. A Figura 9 a seguir mostra um exemplo de raytracing para o modelo obtido através da interpretação convencional mostrado na Figura 7.

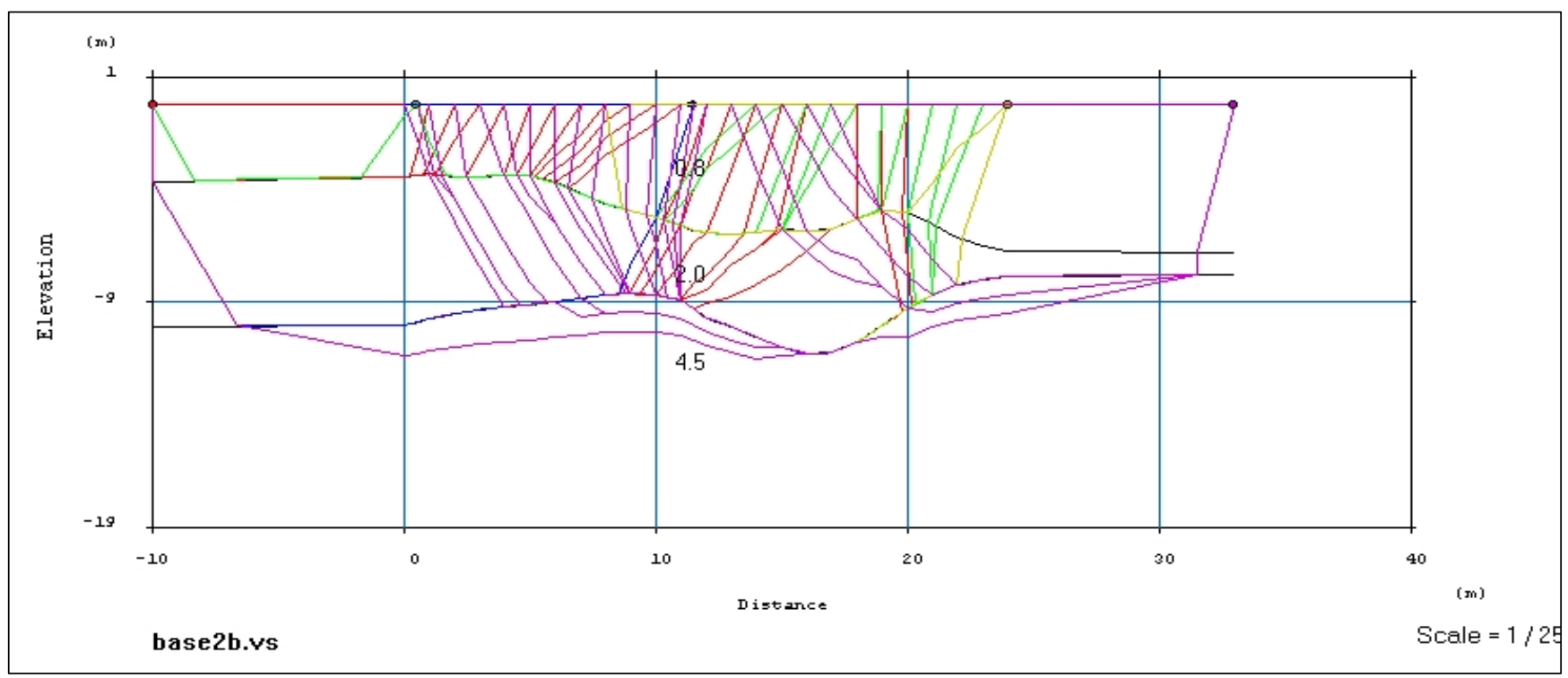

Figura 9 - Raytracing da seção sísmica resultante da interpretação convencional, executada para se determinar as curvas tempoXdistância mostrada na Figura 10.

A Figura 10 mostra a comparação entre as curvas tempoXdistância obtidas com os dados de campo e as curvas tempoXdistância resultantes da modelagem para a interpretação convencional. A Figura 11 mostra as mesmas curvas para a interpretação feita com a inversão tomográfica.

Estas duas Figuras mostram que nos dois casos houve um bom ajuste entre os dados observados (linhas azuis) com os dados calculados pela inversão (linhas pretas). Pode-se concluir a partir destes resultados, que quando o local é propício à realização de ensaios de refração, tanto faz utilizar uma ou outra técnica de interpretação que bons resultados serão conseguidos.

No caso do Local 2, percebe-se que no imageamento tomográfico aparecem zonas de velocidades diferentes na primeira camada (Figura 8) que não são determinadas na interpretação convencional (Figura 7).

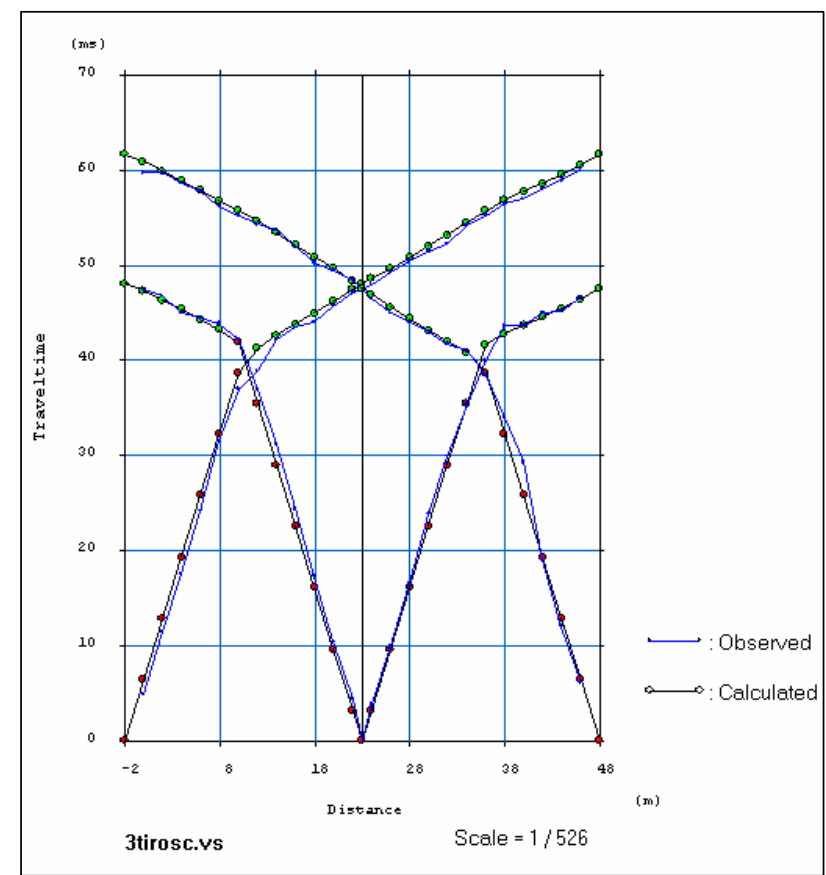

Figura 10 - Comparação entre as curvas tempo $X$ distância obtidas com dados observados (azul) e calculados (pretos) para a interpretação convencional utilizando duas camadas. 


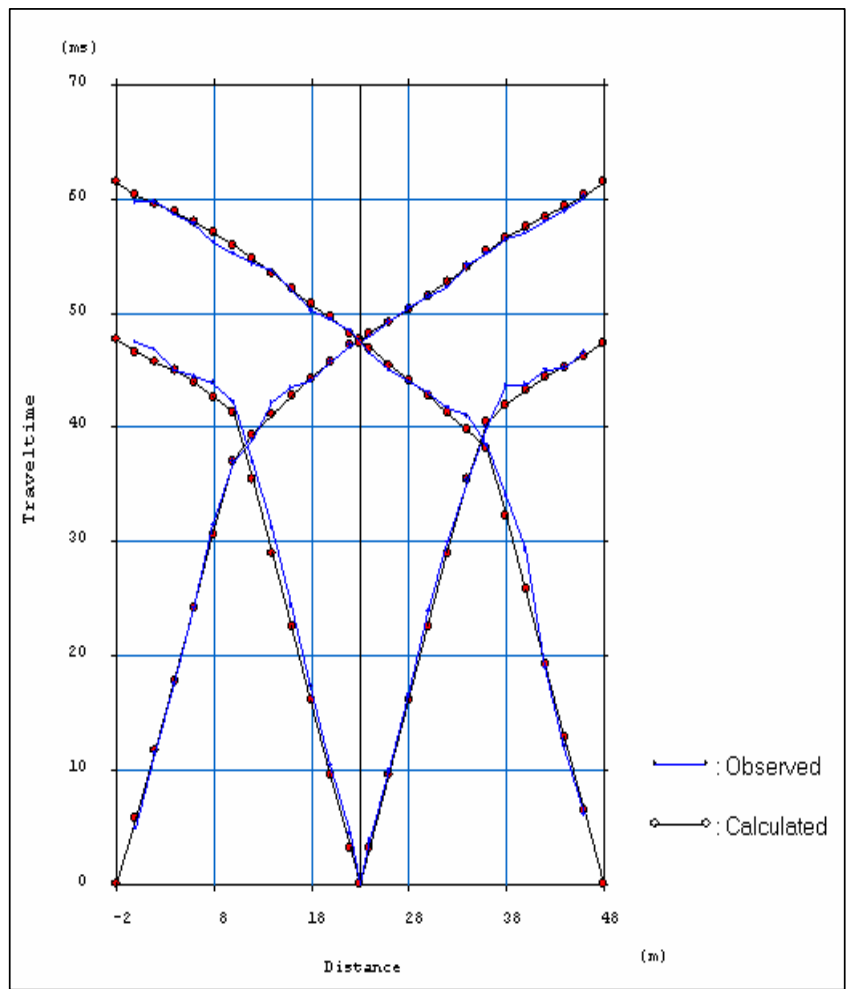

Figura 11 - Comparação entre as curvas tempo $X$ distância obtidas com dados observados (azul) e calculados (pretos) para a interpretação com inversão tomográfica.

A Figuras 12 mostra a comparação entre as curvas tempoXdistância obtidas com os dados observados e as curvas calculadas através da modelagem direta da seção sísmica obtida com a interpretação convencional. A Figura 13 mostra as mesmas curvas para a interpretação com inversão tomográfica.

A comparação que pode ser entre as Figuras 12 e 13 mostra claramente que houve um ajuste muito melhor para os dados obtidos a partir da seção sísmica gerada pela interpretação tomográfica do que aqueles da interpretação convencional.

Pode-se concluir à partir deste resultados que quando houver camadas anisotrópicas com relação à velocidade de propagação das ondas $\mathrm{P}$ e/ou uma irregularidade muito grande nas interfaces das camadas refratoras a utilização de técnicas de inversão tomográficas são superiores em termos qualitativos com relação às técnicas convencionais de interpretação.

Com a utilização da inversão tomográfica, pode-se mesmo determinar estruturas que possuam menor velocidade propagação de ondas $P$ sob camadas de maiores velocidades e até mesmo cavidades em subsuperfície (Sheehan et al. 2005), sendo este procedimento uma grande limitação da sísmica de refração convencional.

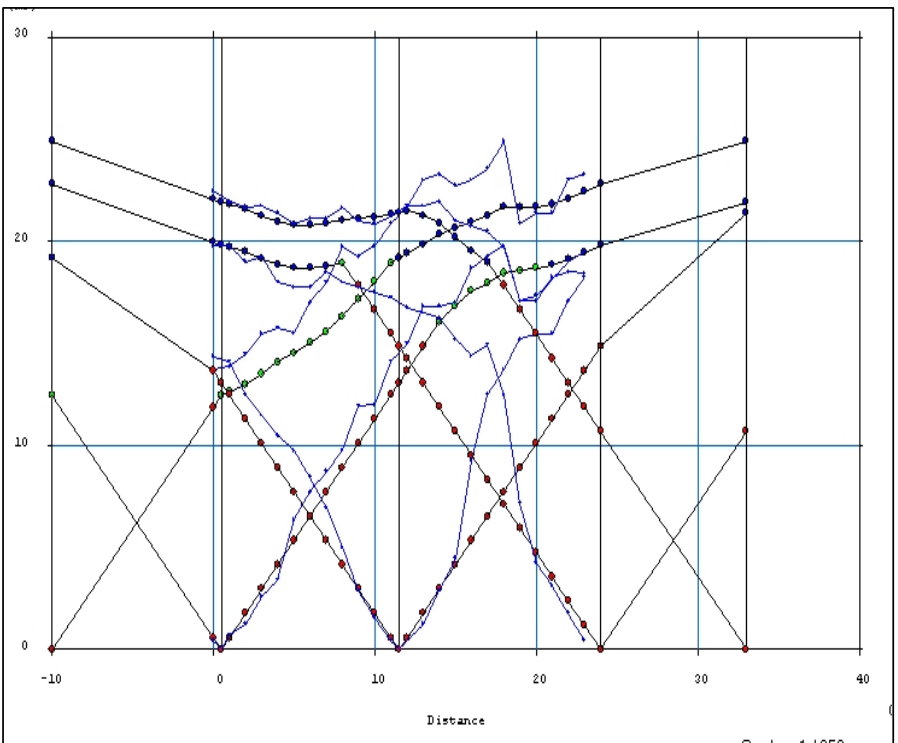

Figura 12 - Comparação entre as curvas tempo $X$ distância obtidas com dados observados (azul) e calculados (pretos) para a interpretação convencional utilizando três camadas.

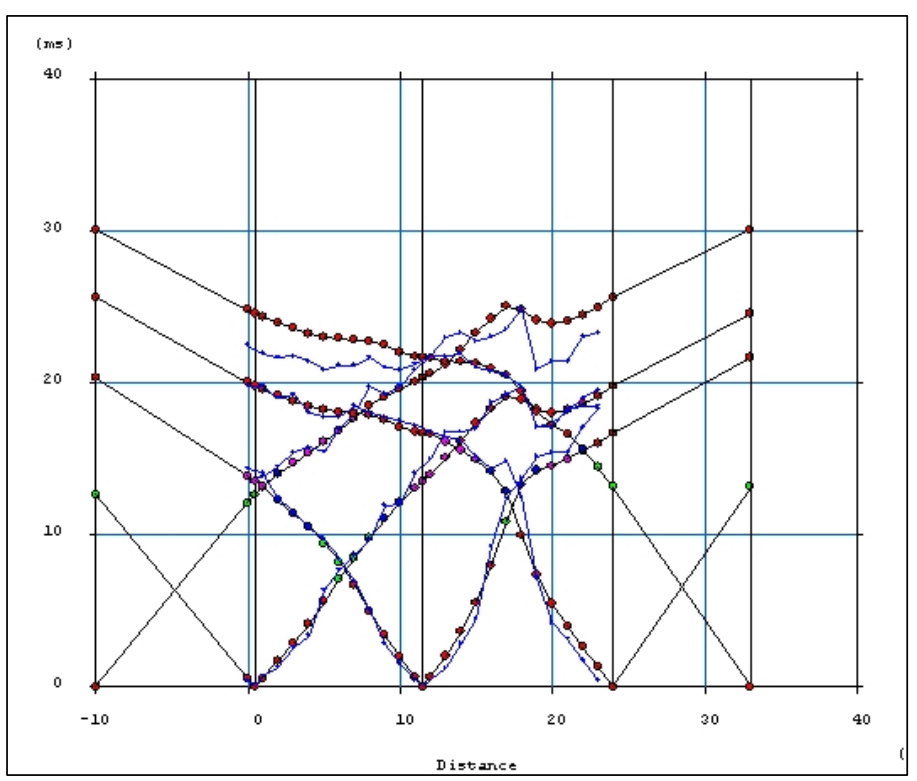

Figura 13 - Comparação entre as curvas tempo $X$ distância obtidas com dados observados (azul) e calculados (pretos) para a interpretação com inversão tomográfica.

Deve-se, no entanto tomar cuidado na utilização dos programas de inversão tomográfica, pois a maioria gera resultado além da área de cobertura dos raios sísmicos, podendo criar artefatos que levarão à interpretação enganosa.

Outra observação que deve ser feita é quanto à quantidade de pontos de geração de ondas: como regra geral deve ser utilizado um número maior de pontos de 
geração de ondas para a interpretação com inversão tomográfica do que para a interpretação convencional, para aumentar o número de raios sísmicos dentro do meio estudado.

\section{Agradecimentos}

Os autores agradecem ao técnico Francisco Garcia Barrera (Paco) pelo auxilio nos trabalhos de campo.

\section{Referências}

McGee, J. E., and Palmer, R. L., 1967. Early refraction practices, in Musgrave, AW,. Ed., Seismic refraction prospecting: Soc. Expl. Geophys., 3-11.

Sheehan, J. R., Doll, W. E., and Wayne A. Mandell, W. A., 2005. An Evaluation of Methods and Available Software for Seismic Refraction Tomography Analysis. JEEG, Volume 10, Issue 1, pp. 21-34

Sheehan, J. R., Doll, W. E., Watson, D.B. and Wayne A. Mandell, W. A.., 2005. Application of Seismic Refraction Tomography to Karst Cavities: U.S. Geological Survey Scientific Investigations Report 2005-5160

Sjogren, B. 2000. A brief study of the generalized reciprocal method and of same limitations of the method: Geophysical Prospecting 48, 815-834. 